\title{
Early prognostication of neurological outcome by heart rate variability in adult patients with out-of-hospital sudden cardiac arrest
}

\author{
Hiroshi Endoh ${ }^{1,2^{*}}$ (D) Natuo Kamimura ${ }^{1,2}$, Hiroyuki Honda ${ }^{2}$ and Masakazu Nitta ${ }^{2}$
}

\begin{abstract}
Background: Most deaths of comatose survivors of out-of-hospital sudden cardiac arrest result from withdrawal of life-sustaining treatment (WLST) decisions based on poor neurological prognostication and the family's intention. Thus, accurate prognostication is crucial to avoid premature WLST decisions. However, targeted temperature management (TTM) with sedation or neuromuscular blockade against shivering significantly affects early prognostication. In this study, we investigated whether heart rate variability (HRV) analysis could prognosticate poor neurological outcome in comatose patients undergoing hypothermic TTM.

Methods: Between January 2015 and December 2017, adult patients with out-of-hospital sudden cardiac arrest, successfully resuscitated in the emergency department and admitted to the intensive care unit of the Niigata University in Japan, were prospectively included. All patients had an initial Glasgow Coma Scale motor score of 1 and received hypothermic TTM (at $34^{\circ} \mathrm{C}$ ). Twenty HRV-related variables (deceleration capacity; 4 time-, 3 geometric-, and 7 frequency-domain; and 5 complexity variables) were computed based on RR intervals between 0:00 and 8:00 am within $24 \mathrm{~h}$ after return of spontaneous circulation (ROSC). Based on Glasgow Outcome Scale (GOS) at 2 weeks after ROSC, patients were divided into good outcome (GOS 1-2) and poor outcome (GOS 3-5) groups.
\end{abstract}

Results: Seventy-six patients were recruited and allocated to the good $(n=22)$ or poor $(n=54)$ outcome groups. Of the 20 HRV-related variables, In very-low frequency (In VLF) power, detrended fluctuation analysis (DFA) (a1), and multiscale entropy (MSE) index significantly differed between the groups $(p=0.001)$, with a statistically significant odds ratio $(\mathrm{OR})$ by univariate logistic regression analysis $(p=0.001)$. Multivariate logistic regression analysis of the 3 variables identified In VLF power and DFA (a 1$)$ as significant predictors for poor outcome $(O R=0.436, p=0.006$ and $\mathrm{OR}=0.709, p=0.024$, respectively). The area under the receiver operating characteristic curve for $\mathrm{In}$ VLF power and DFA (a1) in predicting poor outcome was 0.84 and 0.82 , respectively. In addition, the minimum value of In VLF power or DFA (a1) for the good outcome group predicted poor outcome with sensitivity $=61 \%$ and specificity $=100 \%$.

Conclusions: The present data indicate that HRV analysis could be useful for prognostication for comatose patients during hypothermic TTM.

Keywords: Prognostication, Glasgow outcome scale, Heart rate variability, Targeted temperature management, Out-ofhospital sudden cardiac arrest

\footnotetext{
* Correspondence: endoh@med.niigata-u.ac

'Department of Emergency \& Critical Care Medicine, Niigata University

Faculty of Medicine, 1-757 Asahimachi-dori, Chuo-ku, Niigata 951-8520, Japan

${ }^{2}$ Advanced Emergency and Critical Care Center, Niigata University Medical \&

Dental Hospital, 1-754 Asahimachi-dori, Chuo-ku, Niigata 951-8520, Japan
}

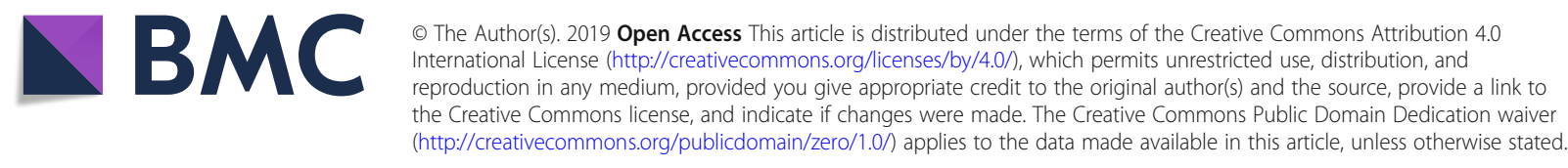




\section{Background}

Despite progress in practices of cardiopulmonary resuscitation and post-cardiac arrest care, most survivors of out-ofhospital sudden cardiac arrest remain comatose due to severe hypoxic-ischemic brain injury [1]. However, most deaths in these patients result from withdrawal of lifesustaining treatment (WLST) decisions based on poor neurological prognostication and the family's intention [2, 3]. Thus, accurate prognostication of poor neurological outcome is crucial not only to avoid premature WLST decisions, but also to avoid unnecessary examinations or expensive treatments and lengthy anxious waiting periods for families of patients who will have a poor outcome.

Recent cardiopulmonary resuscitation guidelines strongly recommend targeted temperature management (TTM) for comatose survivors after return of spontaneous circulation (ROSC) [4, 5]. TTM with sedation or a neuromuscular blocking agent for control of shivering significantly affects early and accurate prognostication [6, 7]. The diagnostic accuracy of a robust prognosticator for poor outcome is recommended to have a specificity of $>95 \%$ (negative predicting value $<5 \%$ ) in clinical settings [6-8].

Traditionally, heart rate variability (HRV) provides a convenient and noninvasive method to assess the balance between sympathetic and parasympathetic activities of the autonomic nervous system [9]. Numerous studies have shown that time- or frequency-domain variables of HRV can reflect clinical severity and prognosis in intensive care unit (ICU) patients [10, 11]. Recently, complexity variables based on the nonlinear fractal dynamics of human HRV have been shown to provide additional prognostic information and complement traditional time- and frequency-domain variables $[12,13]$.

Several prior studies have indicated that HRV-related variables may predict the outcome of comatose patients after ROSC. Huikuri et al. reported that ROSC patients had a lower standard deviation of all RR intervals (SDNN) or high-frequency power per $24 \mathrm{~h}$ compared with noncardiac arrest patients [14]. Dougherty and Burr reported that the SDNN and low-frequency power per $24 \mathrm{~h}$ were significantly related to 1-year mortality [15]. Chen et al. showed that normalized low-frequency power of a 10-min RR interval was a significant predictor of 24-h mortality [16]. However, the post ROSC patients in these studies were not treated with hypothermic TTM.

In the present study, we investigated HRV-related prognosticators within $24 \mathrm{~h}$ after ROSC in patients with an initial Glasgow Coma Scale (GCS) motor score of 1 undergoing hypothermic TTM.

\section{Methods}

This prospective, observational, single-center study was approved by the local ethical committee of the Medical Faculty of Niigata University.

\section{Participants}

Between January 1, 2015, and December 31, 2017, adult patients with out-of-hospital sudden cardiac arrest who were transferred to the emergency department at Niigata University Hospital and successfully resuscitated were consecutively enrolled. All resuscitated patients were admitted to the Niigata University Hospital ICU.

Patients were eligible for participation if they met the following criteria: more than 16 years old, GCS motor scale of 1 at first evaluation after ROSC, and sinus rhythm. Exclusion criteria were as follows: traumatic cardiac arrest, cardiac arrest due to cerebral origins, normothermic TTM $\left(36^{\circ} \mathrm{C}\right)$, new onset of atrial fibrillation or atrial flutter rhythm, and hemodynamically unstable patients (severe hypotension).

\section{Study protocol}

All patients were mechanically ventilated to maintain normocapnia $\left(\mathrm{PaCO}_{2} \quad 35-45 \mathrm{mmHg}\right)$ under sedation with continuous intravenous infusion of midazolam $\left(0.1-0.2 \mathrm{mg} \mathrm{kg}^{-1} \mathrm{~h}^{-1}\right)$ with fentanyl $\left(0.1-0.2 \mu \mathrm{g} \mathrm{kg}^{-1}\right.$ $\left.\mathrm{h}^{-1}\right)$. Rocuronium bromide was continuously infused to mitigate uncontrollable shivering (500-750 $\mathrm{gg}$ $\left.\mathrm{kg}^{-1} \mathrm{~h}^{-1}\right)$.

TTM targeting $34^{\circ} \mathrm{C}$ of bladder temperature for 24 $\mathrm{h}$ was introduced and maintained with an intravascular cooling device (Thermogard $\mathrm{XP}^{\oplus}$, Asahikasei Zoll medical, Japan) or a body surface cooling device (Arctic Sun $2000^{\circ}$, IMI, Japan). During hypothermia, a mean arterial pressure (MAP) $>60 \mathrm{mmHg}$ was maintained with fluid resuscitation and/or continuous infusion of noradrenaline. All patients were rewarmed at a rate of $0.25^{\circ} \mathrm{Ch}^{-1}$. Patients who could not maintain MAP $>60 \mathrm{mmHg}$ with these methods were excluded from the study. The treating ICU physicians were blinded to the following HRV-related metrics during study period.

\section{Assessment of decelerating capacity; time-, frequency-, and geometrical-domain; and complexity variables of HRV}

Electrocardiograms (ECG) were continuously monitored with a bedside monitor (IntelliVue $\mathrm{MP70}^{\circ}$, Philips, Japan), and the ECG wave data were captured at a sampling frequency of $250 \mathrm{~Hz}$ with 14-bit resolution and automatically stored in the dedicated server. RR intervals between 0:00 am and 8:00 am within the first $24 \mathrm{~h}$ post-ROSC were identified by wqrs algorithm [17] and stored as a comma-separated value file (CSV) after 5 points moving averaging. The 8 -h recording was started at midnight because this timeframe had fewer external stimuli such as physiological examinations or family visits. 
Sinus rhythm was considered only when RR intervals were between 300 and $2000 \mathrm{~ms}$ and differed s $20 \%$ from the average of five preceding sinus rhythm $\mathrm{RR}$ intervals, and consecutive $\mathrm{RR}$ interval differences were $\leq 200 \mathrm{~ms}$ [18]. Any RR intervals not based on the above sinus rhythm criteria were replaced with the average value of the five preceding sinus rhythm RR intervals. When the replacement number divided by the entire RR intervals (replacement ratio) was > $20 \%$, the patient was excluded from this study.

Decelerating capacity (DC) was computed using the software program calc-prsa (version 1.3.0) that was developed based on the phase-rectified signal averaging technique [19].

The method used for time-, frequency-, and geometric-domain HRV analysis has been described elsewhere and adhered to the standards developed by the Task Force of the European Society of Cardiology and the North American Society of Pacing and Electrophysiology [20].

For the time-domain variables, the average of all $R R$ intervals $(\mathrm{AVNN})$, the $\mathrm{SDNN}$, square root of the mean of the squares of differences between adjacent RR intervals (rMSSD), and the percentage of differences between adjacent RR intervals > $50 \mathrm{~ms}$ (pNN50) were computed.

For the frequency-domain variables, a Lomb-Scargle periodogram was plotted to measure the spectral power of the ultra-low-frequency range (ULF, 0$0.003 \mathrm{~Hz}$ ), the very-low-frequency range (VLF, 0.003$0.04 \mathrm{~Hz}$ ), the low-frequency range (LF, 0.04-0.15 Hz), the high-frequency range $(\mathrm{HF}, 0.15-0.4 \mathrm{~Hz})$, the total power (TP, $0-0.4 \mathrm{~Hz})$, the ratio of low- to highfrequency power (LF/HF), and the slope of the linear interpolation between $10^{-4}$ and $10^{-2} \mathrm{~Hz}$ of the spectrum in a log-log scale (power-law slope, exponent $\beta$ ). All measured powers were expressed as natural logarithm $(\ln )$.

For the geometric-domain variables, the total number of all $R R$ intervals was divided by the height of the histogram of all $R R$ intervals measured on a discrete scale with bins of $7.185 \mathrm{~ms}$ (triangular index), and RR interval was plotted as a function of the previous one (Poincaré plot). SD1 and SD2 are the two dispersions (standard deviations [SD]) of projections of the Poincaré plot on the line of identity $(y=x)$ and on the line perpendicular to the line of identity $(y=-$ $x)$, respectively [21].

For the complexity variables, approximate entropy (ApEn) and sample entropy (SampEn) were computed with a parameter of $m=2$ and similarity criterion = $20 \%$ of SD [22]. Multiscale entropy (MSE) index was defined as the sum of the sample entropy at a scale factor of 1-20 [23]. Detrended fluctuation analysis
(DFA) was measured to quantify fractal scaling properties of the RR interval [24]. The scaling properties were defined separately for short-term $(4 \leq n \leq 16$ beats, $\left.\alpha_{1}\right)$ and long-term $\left(n>16\right.$ beats, $\left.\alpha_{2}\right)$ RR intervals.

DC, rMSSD, pNN50, In LF power, In HF power, and LF/HF were computed from the segment of 512 $R R$ intervals, and the averaged values of the entire $R R$ intervals were calculated. AVNN, SDNN, triangular index, In total power, ln ULF power, In VLF power, ApEn, SampEn, and MSE index were computed for the entire RR intervals. SD1, SD2, DFA $\left(\alpha_{1}\right)$, and DFA $\left(\alpha_{2}\right)$ were computed from the segment of 1000 RR intervals, and the averaged values of the entire $R R$ intervals were calculated.

All variables except DC were computed with programs downloaded from PhysioNet (https://physionet.org /physiotools/matlab/wfdb/wfdb-app-matlab/).

\section{Study endpoint}

The primary endpoint was Glasgow Outcome Scale (GOS) on the 14th day after ROSC. The good outcome group included patients with a good recovery (GOS 1) or moderate disability (GOS 2). The poor outcome group included patients with severe disability (GOS 3), a persistent vegetative state (GOS 4), or death (GOS 5). The GOS level was prospectively assessed by ICU physicians until death or hospital discharge.

\section{Statistical analyses}

Categorical variables were presented as numbers or percentage and compared using the chi-squared test or Fisher's exact test. Continuous variables were presented as median (interquartile range) and compared using the Mann-Whitney $U$ test. Univariate logistic regression analysis for poor outcome was performed on each HRV-related variable. Variables were included in the multivariate logistic regression analysis if $p=$ 0.001 (both Mann-Whitney $U$ test and univariate logistic regression analysis). Results were presented as odds ratios (OR) and 95\% confidence intervals (CI).

The receiver operating characteristic (ROC) curve was plotted, and the area under the curve (AUC) was calculated to evaluate the predictive performance of HRV-related variables for poor outcome. Youden index was used to calculate the optimal cut off value. Sensitivity and specificity were determined for the selected cutoff value. In addition, sensitivity, specificity, positive predictive value (PPV), negative predictive value (NPV), and false-positive ratio (FPR) for poor outcome were calculated by dichotomy of the minimum values of the patients with good outcome. 
Two-sided $p$ values $<0.05$ were considered statistically significant. All analyses were performed using STATA/SE package version 15.0 (StataCorp, College Station, TX, USA).

\section{Results}

\section{Patient characteristics}

After the exclusion of patients, a total of 77 patients were recruited; however, one patient with replacement rate $>20 \%$ was excluded. Thus, 76 patients were enrolled and divided by GOS on the 14th day after
ROSC into good outcome $(n=22)$ or poor outcome $(n=54)$ groups (Fig. 1).

The median replacement rate of good or poor outcome groups was $0.13 \%$ or $0.38 \%$, respectively, with no statistically significant difference $(p=0.642)$.

Patient characteristics are shown in Table 1. There was no significant difference in age, gender, Acute Physiology and Chronic Health Evaluation (APACHE) II score, and Sequential Organ Failure Assessment (SOFA) Score (day 1) between good and poor outcome groups.

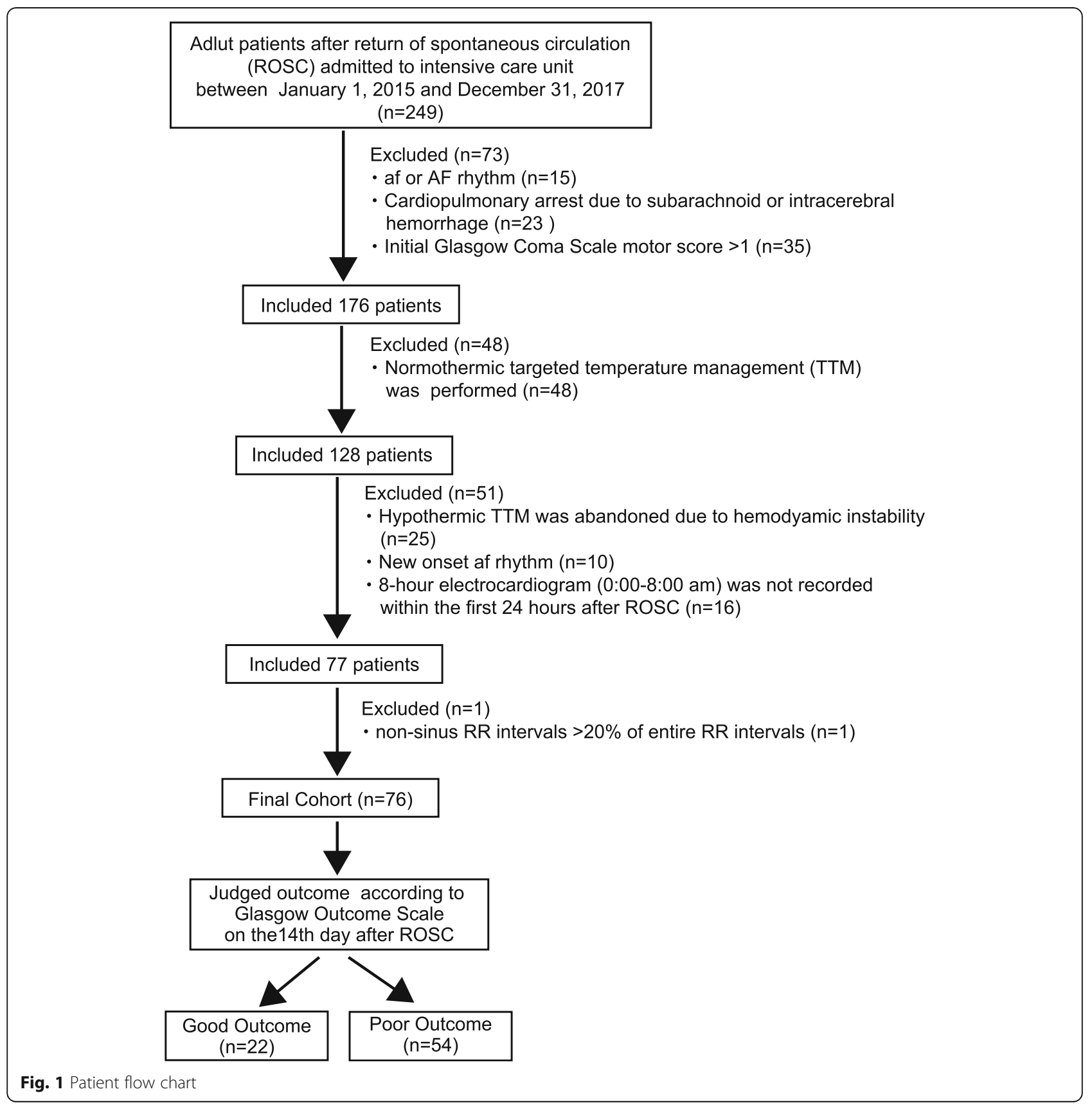


Table 1 Comparison of patient characteristics and HRV-related variables between good and poor outcomes

\begin{tabular}{|c|c|c|c|c|}
\hline Patient characteristics /HRV-related variable & Total $(n=76)$ & Good outcome $(n=22)$ & Poor outcome $(n=54)$ & $p$ \\
\hline Age (years) & $61(46-76)$ & $58(49-72)$ & $61(45-77)$ & 0.748 \\
\hline Gender (F/M) (n) & $26 / 50$ & $7 / 15$ & $19 / 35$ & 0.779 \\
\hline APACHE \| score & $28(26-31)$ & $27(26-29)$ & $28(27-32)$ & 0.185 \\
\hline SOFA score, day 1 & $11(8-13)$ & $10(7-11)$ & $11(8-14)$ & 0.153 \\
\hline DC & $1.83(0.92-3.34)$ & $2.69(1.23-5.32)$ & $1.64(0.78-2.77)$ & 0.037 \\
\hline AVNN (ms) & $699(605-827)$ & $804(698-842)$ & $677(574-788)$ & 0.009 \\
\hline SDNN (ms) & $40.9(25.3-57.8)$ & $47.6(34.7-71.5)$ & $35.5(23.8-55.4)$ & 0.090 \\
\hline rMSSD (ms) & $10.4(4.9-19.8)$ & $15.3(6.4-24.4)$ & $9.1(4.2-17.0)$ & 0.111 \\
\hline pNN50(\%) & $0.88(0.16-3.76)$ & $1.17(0.16-3.76)$ & $0.77(0.16-3.47)$ & 0.518 \\
\hline Triangular index & $7.3(5.1-11.1)$ & $9.8(6.7-15.3)$ & $6.6(4.9-10.3)$ & 0.018 \\
\hline Poincaré plot, SD1 (ms) & $7.5(3.5-14.8)$ & $11.5(4.5-19.7)$ & $7.2(3.1-12.9)$ & 0.088 \\
\hline Poincaré plot, SD2 (ms) & $17.4(10.0-29.9)$ & $31.0(21.1-43.0)$ & $13.3(7.4-22.6)$ & 0.001 \\
\hline In total power $\left(\mathrm{ms}^{2}\right)$ & $8.06(7.15-8.80)$ & $8.48(7.77-9.46)$ & $7.84(7.03-8.70)$ & 0.062 \\
\hline In ULF power $\left(\mathrm{ms}^{2}\right)$ & $7.83(6.90-8.63)$ & $8.06(7.39-8.81)$ & $7.72(6.80-8.59)$ & 0.140 \\
\hline In VLF power $\left(\mathrm{ms}^{2}\right)$ & $4.83(3.73-5.98)$ & $6.06(5.49-7.12)$ & $4.41(3.14-5.22)$ & 0.001 \\
\hline In LF power $\left(\mathrm{ms}^{2}\right)$ & $3.65(1.72-4.59)$ & $4.38(3.54-5.30)$ & $3.10(1.36-4.33)$ & 0.002 \\
\hline In HF power $\left(\mathrm{ms}^{2}\right)$ & $3.53(2.39-4.72)$ & $3.96(2.71-5.08)$ & $3.11(1.99-4.67)$ & 0.195 \\
\hline $\mathrm{LF} / \mathrm{HF}$ & $0.98(0.52-2.04)$ & $2.23(1.10-3.72)$ & $0.73(0.40-1.42)$ & 0.001 \\
\hline Power law $(\beta)$ & $-1.45(-1.74$ to -1.20$)$ & $-1.36(-1.48$ to -1.05$)$ & $-1.56(-1.80$ to -1.31$)$ & 0.015 \\
\hline DFA $\left(a_{1}\right)$ & $0.79(0.64-0.98)$ & $0.98(0.87-1.22)$ & $0.71(0.60-0.86)$ & 0.001 \\
\hline DFA $\left(a_{2}\right)$ & $0.92(0.77-1.12)$ & $1.10(0.88-1.29)$ & $0.88(0.71-1.01)$ & 0.003 \\
\hline ApEn & $0.55(0.27-0.84)$ & $0.59(0.30-0.95)$ & $0.51(0.26-0.81)$ & 0.336 \\
\hline SampEn & $0.37(0.17-0.60)$ & $0.38(0.23-0.79)$ & $0.36(0.16-0.55)$ & 0.348 \\
\hline MSE index & $10.8(3.5-19.4)$ & $19.0(14.8-22.6)$ & $8.3(2.9-13.6)$ & 0.001 \\
\hline
\end{tabular}

All values are expressed as $n$ or median (interquartile range)

Abbreviations: AVNN average of all RR intervals, APACHE Acute Physiology and Chronic Health Evaluation, ApEn approximate entropy, DC decelerating capacity, DFA detrended fluctuation analysis, $F$ female, $H F$ high frequency, $H R V$ heart rate variability, $L F$ low frequency, $L F / H F$ ratio of low- to high-frequency power, In natural logarithm, M male, MSE multiscale entropy, Power law slope of the regression of power spectrum in log-log scale, $p N N 50 \%$ of successive RR intervals differing > $50 \mathrm{~ms}, r M S S D$ square root of the mean of the squares of differences between adjacent RR intervals, SampEn sample entropy, SDNN standard deviation of all RR intervals, SD1 and SD2 standard deviations of short and long axis of Poincaré plot, SOFA Sequential Organ Failure Assessment, Triangular index total number of all RR intervals divided by the height of the histogram of all RR intervals, ULF ultra-low frequency, VLF very-low frequency

\section{Comparisons of HRV-related variables between poor and good outcomes}

Table 1 also shows comparisons of $20 \mathrm{HRV}$-related variables. There was a significant difference in DC $(p=$ $0.037)$, AVNN $(p=0.009)$, triangular index $(p=0.018)$, SD2 $(p=0.001)$, In VLF power $(p=0.001)$, ln LF power $(p=0.002)$, LF/HF $(p=0.001)$, power law $(\beta)(p=0.015)$, DFA $\left(\alpha_{1}\right) \quad(p=0.001)$, DFA $\left(\alpha_{2}\right) \quad(p=0.003)$, and MSE index $(p=0.001)$ between good and poor outcome groups. The curves of the MSE of poor and good outcome groups are shown in Additional file 1: Figure S1.

Table 2 shows OR and 95\% CI of 20 HRV-related variables for poor outcome by univariate logistic regression analysis. Significant univariate variables for poor outcome were DC $(p=0.033), \operatorname{AVNN}(p=0.012)$, In total power $(p=0.032)$, In VLF power $(p=0.001)$, ln LF power $(p=0.003)$, LF/HF $(p=0.002)$, DFA $\left(\alpha_{1}\right)$ $(p=0.001)$, DFA $\left(\alpha_{2}\right)(p=0.003)$, and MSE index $(p=$ $0.001)$.

Table 2 also shows OR and 95\% CI of variables by multivariate logistic regression analysis of the 3 variables that were statistically significant by both Mann-Whitney $U$ test and univariate logistic regression analysis $(p=0.001)$. In VLF power and DFA $\left(\alpha_{1}\right)$ were significant predictors for poor outcome $(\mathrm{OR}=0.436, p=0.006$ and $\mathrm{OR}=0.709, p=$ 0.024 , respectively).

Figure 2 shows a box-and-whisker plot, ROC curve, AUC, and optimal cutoff value for the $5 \mathrm{HRV}$-related variables that were statistically significant by Mann-Whitney $U$ test $(p=0.001)$. The AUC for In VLF power and DFA $(\alpha 1)$ were $0.84 \quad(95 \% \mathrm{CI}=0.75-0.93)$ and $0.82(95 \% \mathrm{CI}=0.72-$ 0.91), respectively. The combination of both variables yielded a higher predictive performance (AUC $=0.88$, $95 \% \mathrm{CI}=0.80-0.95)$. The AUC, cutoff value, sensitivity, and 
Table 2 Univariate and multivariate logistic regression analyses of HRV-related variables for prediction of poor outcome

\begin{tabular}{|c|c|c|c|}
\hline HRV-related variable & Odds ratio $(95 \% \mathrm{Cl})$ & $z$ & $p$ \\
\hline \multicolumn{4}{|c|}{ Univariate logistic regression analysis } \\
\hline DC & $0.819(0.681-0.984)$ & -2.13 & 0.033 \\
\hline AVNN (ms) & $0.995(0.992-0.999)$ & -2.52 & 0.012 \\
\hline SDNN (ms) & $0.990(0.977-1.003)$ & -1.53 & 0.127 \\
\hline rMSSD (ms) & $0.965(0.929-1.003)$ & -1.81 & 0.070 \\
\hline pNN50(\%) & $0.985(0.924-1.051)$ & -0.45 & 0.654 \\
\hline Triangular index & $0.915(0.834-1.004)$ & -1.89 & 0.059 \\
\hline Poincaré plot, SD1 (ms) & $0.982(0.951-1.015)$ & -1.06 & 0.288 \\
\hline Poincaré plot, SD2 (ms) & $0.985(0.968-1.001)$ & -1.79 & 0.073 \\
\hline In total power $\left(\mathrm{ms}^{2}\right)$ & $0.626(0.409-0.960)$ & -2.15 & 0.032 \\
\hline In ULF power $\left(\mathrm{ms}^{2}\right)$ & $0.700(0.469-1.043)$ & -1.75 & 0.080 \\
\hline In VLF power $\left(\mathrm{ms}^{2}\right)$ & $0.373(0.224-0.620)$ & -3.80 & 0.001 \\
\hline In LF power $\left(\mathrm{ms}^{2}\right)$ & $0.598(0.424-0.845)$ & -2.92 & 0.003 \\
\hline In HF power $\left(\mathrm{ms}^{2}\right)$ & $0.802(0.593-1.084)$ & -1.44 & 0.151 \\
\hline $\mathrm{LF} / \mathrm{HF}$ & $0.472(0.304-0.733)$ & -3.35 & 0.002 \\
\hline Power law $(\beta)$ & $0.278(0.074-1.038)$ & -1.90 & 0.057 \\
\hline DFA $\left(a_{1}\right)($ per $0.1 \mathrm{U})$ & $0.635(0.501-0.805)$ & -3.76 & 0.001 \\
\hline DFA $\left(a_{2}\right)($ per $0.1 \mathrm{U})$ & $0.702(0.556-0.886)$ & -2.98 & 0.003 \\
\hline ApEn (per $0.1 \mathrm{U}$ ) & $0.930(0.820-1.055)$ & -1.13 & 0.260 \\
\hline SampEn (per $0.1 \mathrm{U}$ ) & $0.911(0.787-1.054)$ & -1.25 & 0.211 \\
\hline MSE index & $0.873(0.811-0.941)$ & -3.56 & 0.001 \\
\hline \multicolumn{4}{|c|}{ Multivariate logistic regression analysis } \\
\hline Ln VLF power & $0.436(0.242-0.784)$ & -2.77 & 0.006 \\
\hline DFA $\left(a_{1}\right)($ per $0.1 \mathrm{U})$ & $0.709(0.523-0.956)$ & -2.26 & 0.024 \\
\hline MSE index & $0.983(0.888-1.088)$ & -0.33 & 0.739 \\
\hline
\end{tabular}

Abbreviations: AVNN average of all RR intervals, ApEn approximate entropy, $\mathrm{Cl}$ confidence interval, $D C$ decelerating capacity, DFA detrended fluctuation analysis, $H F$ high frequency, $H R V$ heart rate variability, $L F$ low frequency, $L F / H F$ ratio of low to high frequency power, In natural logarithm, MSE multiscale entropy, Power law slope of the regression of power spectrum in log-log scale, $p N N 50 \%$ of successive RR intervals differing $>50 \mathrm{~ms}, r M S S D$ square root of the mean of the squares of differences between adjacent RR intervals, SampEn sample entropy, SDNN standard deviation of all RR intervals, SD1and SD2 standard deviations of short and long axis of Poincaré plot, Triangular index total number of all RR intervals divided by the height of the histogram of all RR intervals, ULF ultra-low frequency, VLF very-low frequency

specificity of each HRV-related variable are shown in Additional file 1: Table S1.

Figure 3 shows scatter plots of good or poor outcome patients with corresponding values for ln VLF power ( $x$-axis) and DFA $\left(\alpha_{1}\right)(y$-axis). The dotted lines indicate the minimal value of the patients with good outcome. In VLF power $<3.95$ or DFA $\left(\alpha_{1}\right)<0.70$ predicted poor outcome with sensitivity $=61 \%, \quad$ specificity $=100 \%, \quad P P V=100 \%$, $\mathrm{NPV}=51 \%$, and $\mathrm{FPR}=0 \%$.

\section{Discussion}

We conducted this prospective and exhaustive study to identify early prognosticators among 20 HRV-related variables in post-ROSC comatose patients undergoing hypothermic TTM. Consequently, In VLF power and DFA $\left(\alpha_{1}\right)$ were significant predictors of poor outcome $(\mathrm{OR}=0.463, p=0.006$, and $\mathrm{OR}=0.709, p=0.024$, respectively), with a predictive ability (AUC $=0.84$ and 0.82 , respectively). In addition, the minimal value of $\ln$ VLF power or DFA $\left(\alpha_{1}\right)$ for the patients with good outcome could predict poor outcome with sensitivity $=61 \%$ and specificity $=100 \%$ (Fig. 3), satisfying the requirements for a robust predictor of poor outcome [6-8].

The physiological bases for ULF and VLF power are less clear than LF and HF power. However, In VLF power has been suggested to be a strong risk predictor in patients with reduced left ventricular ejection fraction after acute myocardial infarction [25], post aortic surgery [26], or multiple organ dysfunction (MODF) [27]. DFA is a fractal correlation characterized as free from external interference and requiring non-stationarity. Perkiömäki et al. concluded that a short-term fractal scaling exponent $\left(\alpha_{1}\right)$ predicted fatal cardiovascular events in various populations and might provide more prognostic information than traditional HRV indexes [28]. For example, in a prospective, multicenter study evaluating HRV as a predictor of death after acute myocardial infarction, reduced $\alpha_{1}(<0.75)$ was the most powerful predictor of mortality [29].

Mechanical ventilation or sedation significantly suppresses HRV. Kasaoka et al. showed that LF and HF power and LF/HF per 5 min were significantly higher when ICU patients were breathing spontaneously after extubation [30]. Bradley et al. showed that ICU patients with a low or medium degree of MODF had a greater increase in HRV during sedation interruption, compared with a high degree of MODF [31]. Based on these findings, HRV may have been depressed in our study. However, the depression might be not so severe that differences between outcomes would have been undetectable.

Although hypothermia causes bradycardia physiologically, time-domain variables or frequency-domain variable of HRV during moderate hypothermia was enhanced in patients with poikilothermia [32] or healthy volunteers [33]. Tianien et al. reported that all HRV values based on 24-h RR intervals are higher in post-ROSC comatose patients treated with moderate hypothermia $\left(33^{\circ} \mathrm{C}\right)$ than those treated with normothermia $\left(<38^{\circ} \mathrm{C}\right)$ [34]. In infants with hypoxic ischemic encephalopathy, increased $\mathrm{HF}$ power and AVNN during hypothermia were reported in infants with moderate brain injury [35] or favorable outcome [36] Thus, enhanced HRV produced by moderate hypothermia may counter-act the suppressive effects of mechanical ventilation with sedation in the present study.

\section{Limitations}

Several limitations might affect the present findings. First, this study was conducted at a single institution with a small 

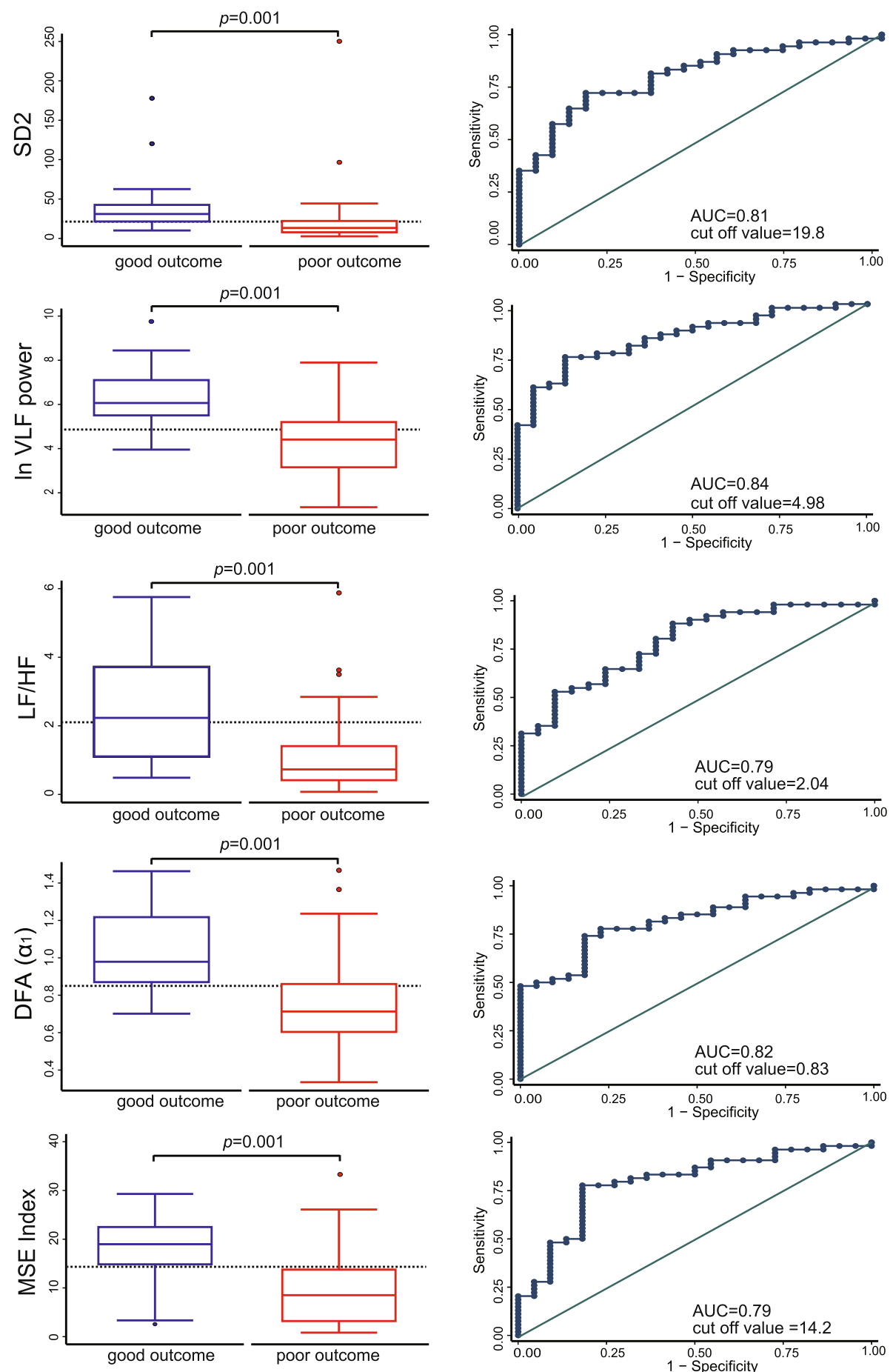

Fig. 2 Box-and-whisker plot, ROC curve, AUC, and cutoff value for the 5 HRV-related variables that were statistically significant by Mann-Whitney $U$ test $(p=0.001)$. The horizontal dotted lines in box-and-whisker plot indicate cutoff values 


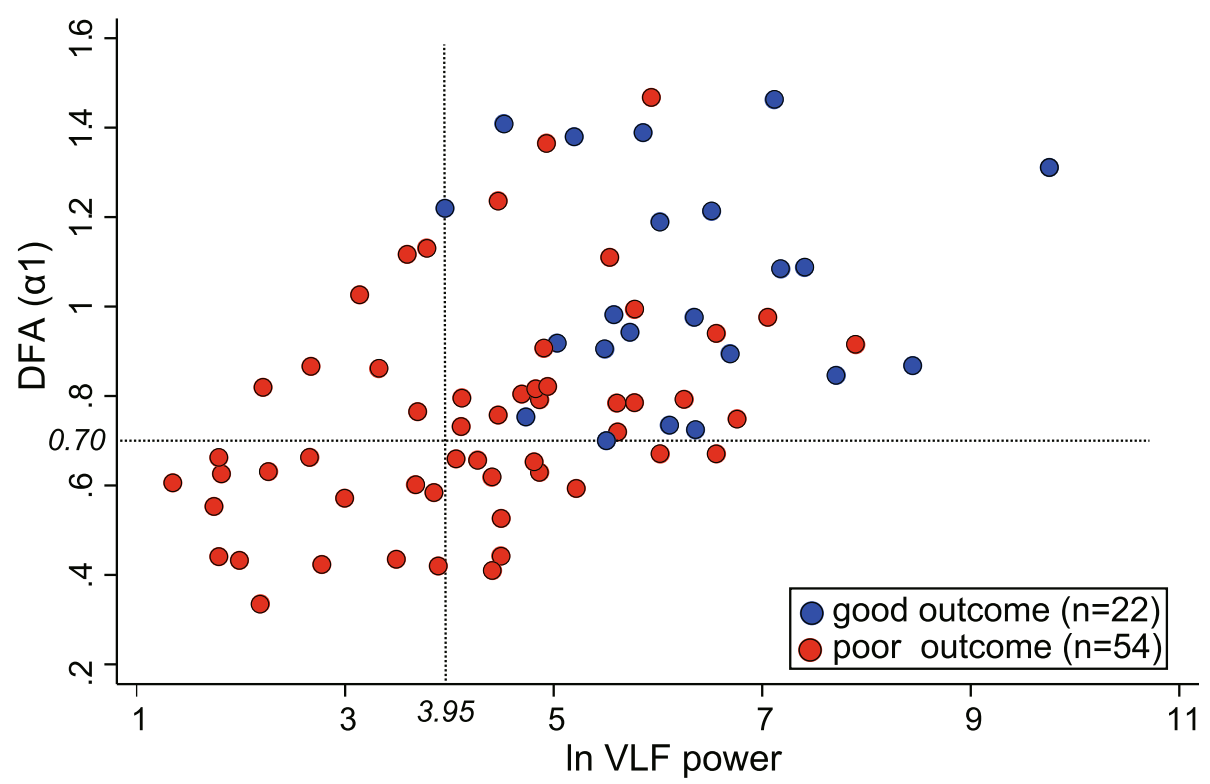

Fig. 3 Scatter plot of patients with good or poor outcome $(n=76)$ with corresponding values for In VLF ( $x$-axis) and DFA $\left(a_{1}\right)(y$-axis). Dashed lines indicate the minimal value of patients with good outcome

sample size. Thus, the cutoff values for HRV herein need to be validated in other studies with a larger cohort. Second, $20 \%$ of patients treated with hypothermic TTM were excluded due to severe hypotension, which may limit the applicability of the data of this study. Third, the 8-h recording time for RR intervals does not strictly adhere to the standard recommendation for HRV measures [20]. Consequently, long-term (24h) HRV variables of SDNN, ULF power, and triangular index may become unreliable. Finally, not all patients had reached the targeted bladder temperature of $34^{\circ} \mathrm{C}$ at the beginning of recording of RR intervals because the recording was scheduled to start at midnight within 24 $h$ after ROSC.

\section{Conclusions}

The present data indicate that HRV analysis could be useful for early prognostication for comatose patients during hypothermic TTM within $24 \mathrm{~h}$ after ROSC. The value of HRV as a prognosticator of poor outcome should be confirmed in a larger study.

\section{Supplementary information}

Supplementary information accompanies this paper at https://doi.org/10. 1186/s13054-019-2603-6.

Additional file 1. Figure S1. MSE curves for poor and good outcome groups. (EPS $1546 \mathrm{~kb}$ )

Additional file 2. Table S1. AUC, cut off value, sensitivity, and specificity of HRV- related variables for poor outcome. (DOCX $18 \mathrm{~kb}$ )

\section{Abbreviations}

APACHE: Acute Physiology and Chronic Health Evaluation;

ApEn: Approximate entropy; AUC: Area under the curve; AVNN: Average of

all RR intervals; Cl: Confidential interval; DC: Decelerating capacity;

DFA: Detrended fluctuation analysis; ECG: Electrocardiogram; FPR: Falsepositive ratio; GCS: Glasgow Coma Scale; GOS: Glasgow Outcome Scale; HF: High frequency; HRV: Heart rate variability; ICU: Intensive care unit; LF: Low frequency; LF/HF: Ratio of low- to high-frequency power; In: Natural logarithm; MAP: Mean arterial pressure; MODF: Multiple organ dysfunction; MSE: Multiscale entropy; NPV: Negative predictive value; OR: Odds ratio; Power law: Slope of the regression of power spectrum in log-log scale; pNN50: Percentage of differences between adjacent RR intervals $>50 \mathrm{~ms}$; PPV: Positive predictive value; rMSSD: Square root of the mean of the squares of differences between adjacent RR intervals; ROC: Receiver operating characteristic; ROSC: Return of spontaneous circulation; SampEn: Sample entropy; SD: Standard deviation; SDNN: Standard deviation of all RR intervals; SD1 and SD1: Standard deviations of short and long axis of Poincaré plot; SOFA: Sequential Organ Failure Assessment; TP: Total power; Triangular index: Total number of all RR intervals divided by the height of the histogram of all RR intervals; TTM: Targeted temperature management; ULF: Ultra-low frequency; VLF: Very-low frequency

\section{Acknowledgements}

We thank Ms. Becky Norquist for assistance with manuscript preparation.

\section{Authors' contributions}

HE and NK were responsible for the conception of the article and drafted the manuscript. $\mathrm{HH}$ helped to create the study design and draft the manuscript. MN helped to conduct statistical analyses. All authors read and approved the final manuscript and take full responsibility for all aspects of the study.

\section{Funding}

All authors declare that the present study was conducted in the absence of any commercial or financial relationships that could be constructed as a potential conflict of interest. 


\section{Availability of data and materials}

Please contact the corresponding author for data requests.

\section{Ethics approval and consent to participate}

The protocol and consent procedures were approved by the institutional review board of author's hospital (No. 2017-0241).

\section{Consent for publication}

Not applicable.

\section{Competing interests}

The authors declare that they have no competing interests.

Received: 18 January 2019 Accepted: 6 September 2019

Published online: 17 October 2019

\section{References}

1. Laver S, Farrow C, Turner D, Nolan J. Mode of death after admission to an intensive care unit following cardiac arrest. Intensive Care Med. 2004;30: 2126-8.

2. Dragancea I, Rundgren $M$, Englund $E$, Friberg $H$, Cronberg $T$. The influence of induced hypothermia and delayed prognostication on the mode of death after cardiac arrest. Resuscitation. 2013;84:337-42.

3. Mulder M, Gibbs HG, Smith SW, Dhaliwal R, Scott NL, Sprenkle MD, Geocadin RG. Awakening and withdrawal of life-sustaining treatment in cardiac arrest survivors treated with therapeutic hypothermia. Crit Care Med. 2014:42:2493-9.

4. Callaway CW, Donnino MW, Fink EL, Geocadin RG, Golan E, Kern KB, Leary M, Meurer WJ, Peberdy MA, Thompson TM, Zimmermanet JL. Part 8: postcardiac arrest care 2015 American Heart Association guidelines update for cardiopulmonary resuscitation and emergency cardiovascular care. Circulation. 2015;132(suppl1):465-82.

5. Nolan JP, Soar J, Cariou A, Cronberg T, Moulaert VRM, Deakin CD, Bottiger BW, Fribergi H, Sunde K, Sandroni C. European Resuscitation Council and European Society of Intensive Care Medicine Guidelines for postresuscitation care 2015 section 5 of the European Resuscitation Council guidelines for resuscitation. 2015. Resuscitation. 2015;95:202-22.

6. Golan E, Barrett K, Alali AS, Duggal A, Jichici D, Pinto R, Morrison L, Scales DC. Predicting neurologic outcome after targeted temperature management for cardiac arrest: systematic review and meta-analysis. Crit Care Med. 2014:42:1919-30.

7. Sandroni C, Cariou A, Cavallaro F, Cronberg T, Friberg H, Hoedemaekers C, Horn J, Nolan JP, Rossetti AO, Soar J. Prognostication in comatose survivors of cardiac arrest: an advisory statement from the European Resuscitation Council and the European Society of Intensive Care Medicine. Intensive Care Med. 2014;40:1816-31.

8. Sandroni C, D'Arrigo S, Nolan JP. Prognostication after cardiac arrest. Crit Care. 2018:22:150.

9. Pomeranz B, Macaulay RJ, Caudill MA, Kutz I, Adam D, Gordon D, Kilborn KM, Barger AC, Shannon DC, Cohen RJ, Benson H. Assessment of autonomic function in humans by heart rate spectral analysis. Am J Phys. 1985;248:151-3.

10. Gang $Y$, Malik M. Heart rate variability in critical care medicine. Curr Opin Crit Care. 2002;8:371-5.

11. Buchman TG, Stein PK, Goldstein B. Heart rate variability in critical illness and critical care. Curr Opin Crit Care. 2002;8:311-5.

12. Voss A, Schulz S, Schroeder R, Baumert M, Caminal P. Methods derived from nonlinear dynamics for analyzing heart rate variability. Phil. Trans. A Math Phys Eng Sci. 2009;367:277-96.

13. Sassi R, Cerutti S, Lombardi F, Malik M, Huikuri HV, Peng CK, Schmidt G, Yamamoto $Y$. Advances in heart rate variability signal analysis: joint position statement by the e-Cardiology ESC Working Group and the European Heart Rhythm Association co-endorsed by the Asia Pacific Heart Rhythm Society. Europace. 2015;17:1341-53.

14. Huikuri HV, Linnaluoto MK, Seppänen T, Airaksinen KE, Kessler KM, Takkunen JT, Myerburg RJ. Circadian rhythm of heart rate variability in survivors of cardiac arrest. Am J Cardiol. 1992;70:610-5.

15. Dougherty CM, Burr RL. Comparison of heart rate variability in survivors and non survivors of sudden cardiac arrest. Am J Cardiol. 1992;70:441-8.

16. Chen WL, Tsai TH, Huang CC, Chen JH, Kuo CD. Heart rate variability predicts short-term outcome for successfully resuscitated patients with outof-hospital cardiac arrest. Resuscitation. 2009;80:1114-8.
17. Zong W, Moody GB, Jiang D. A robust open-source algorithm to detect onset and duration of QRS complexes. Comput Cardiol. 2003;30:737-40.

18. Kisohara M, Stein PK, Yoshida Y, Suzuki M, lizuka N, Carney RM, Watkins LL, Freedland KE, Blumenthal JA, Hayano J. Multi-scale heart rate dynamics detected by phase-rectified signal averaging predicts mortality after acute myocardial infarction. Europace. 2013;15:437-43.

19. Bauer A, Kantelhardt JW, Bunde A, Barthel P, Schneider R, Malik M, Schmidt G. Phase-rectified signal averaging detects quasi-periodicities in nonstationary data. Physica A. 2006;364:423-34.

20. Heart rate variability: standards of measurement, physiological interpretation and clinical use. Task Force of the European Society of Cardiology and the North American Society of Pacing and Electrophysiology. Circulation. 1996; 93: 1043-65.

21. Huikuri HV, Seppänen T, Koistinen MJ, Airaksinen J, Ikäheimo MJ, Castellanos A, Myerburg RJ. Abnormalities in beat-to-beat dynamics of heart rate before the spontaneous onset of life-threatening ventricular Tachyarrhythmias in patients with prior myocardial infarction. Circulation. 1996;93:1836-44

22. Richman JS, Moorman JR. Physiological time-series analysis using approximate entropy and sample entropy. Am J Physiol Heart Circ Physiol. 2000;278:H2039-49.

23. Costa M, Goldberger AL, Peng C-K. Multiscale entropy analysis of biological signals. Phys Rev E. 2005:71:021906.

24. Peng C-K, Havlin S, Stanley HE, Goldberger AL. Quantification of scaling exponents and crossover phenomena in nonstationary heartbeat time series. Chaos. 1995;5:82-7.

25. Huikuri HV, Raatikainen MJ, Moerch-Joergensen R, Hartikainen J, Virtanen V, Boland J, Anttonen O, Hoest N, Boersma LV, Platou ES, et al. Prediction of fatal or near-fatal cardiac arrhythmia events in patients with depressed left ventricular function after an acute myocardial infarction. Eur Heart J. 2009; 30:689-98.

26. Stein PK, Schmieg RE, El-Fouly A, Domitrovich PP, Buchman TG. Association between heart rate variability recorded on postoperative day 1 and length of stay in abdominal aortic surgery patients. Crit Care Med. 2001;29:1738-43.

27. Schmidt H, Müller-Werdan U, Hoffmann T, Francis DP, Piepoli MF, Rauchhaus M, Prondzinsky R, Loppnow H, Buerke M, Hoyer D, et al. Autonomic dysfunction predicts mortality in patients with multiple organ dysfunction syndrome of different age groups. Crit Care Med. 2005;33:19942002

28. Perkiömäki JS, Mäkikallio TH, Huikuri HV. Fractal and complexity measures of heart rate variability. Clin Exp Hypertens. 2005;27:149-58.

29. Tapanainen JM, Thomsen PEB, Køber L, Torp-Pedersen C, Mäkikallio TH, Still AM, Lindgren KS, Huikuri HV. Fractal analysis of heart rate variability and mortality after an acute myocardial infarction. Am J Cardiol. 2002;90:347-52.

30. Kasaoka S, Nakahara T, Kawamura Y, Tsuruta R, Maekawa T. Real-time monitoring of heart rate variability in critically ill patients. J Crit Care. 2010; 25:313-6.

31. Bradley BD, Green G, Ramsay T, Seely AJ. Impact of sedation and organ failure on continuous heart and respiratory rate variability monitoring in critically ill patients: a pilot study. Crit Care Med. 2013;41:433-44.

32. Mackenzie MA, Aengevaeren WR, Hermus AR, Van Der Werf T, Pieters GF, Smals AG, Kloppenborg PW. Electrocardiographic changes during steady mild hypothermia and normothermia in patients with poikilothermia. Clin Sci. 1992;82:39-45.

33. Fleisher LA, Frank SM, Sessler DI, Cheng C, Matsukawa T, Vannier CA. Thermoregulation and heart rate variability. Clin Sci. 1996;90:97-103.

34. Tianien M, Parikka HJ, Mäkijärvi MA, Takkunen OS, Sarna SJ, Roine RO. Arrhythmia and heart rate variability during and after therapeutic hypothermia for cardiac arrest. Crit Care Med. 2009;37:403-9.

35. Goulding RM, Stevenson NJ, Murray DM, Livingstone V, Filan PM, Boylan GB. Heart rate variability in hypoxic ischemic encephalopathy during therapeutic hypothermia. Pediatr Res. 2017:81:609-15.

36. Vesoulis ZA, Rao R, Trivedi SB, Mathur AM. The effect of therapeutic hypothermia on heart rate variability. J Perinatol. 2017:37:679-83.

\section{Publisher's Note}

Springer Nature remains neutral with regard to jurisdictional claims in published maps and institutional affiliations. 